\title{
Benchmarking and its application for caving projects
}

\author{
IT Ross CaveConsult Pty Ltd, Australia
}

\begin{abstract}
The process of benchmarking is commonly used when developing mining projects. As new projects come under scrutiny during the evaluation process, the key drivers, such as development advance rate, drawpoint construction and rate of caving or production ramp-up are, or should be, critically examined.

However, with a limited pool of block/panel caving projects, is the process of benchmarking an appropriate tool to justify significant expenditure? This paper discusses some of the benefits and limitations of benchmarking and highlights some of the issues around establishing the true values ascribed to the parameters. It also highlights some common issues associated with comparing data from different mines.
\end{abstract}

Keywords: benchmarking, block caving, benefits, limitations

\section{Introduction}

When proposing a new mine, a conceptual study will normally indicate how it compares against other mines. The same is true for more advanced levels of study. It is common practice for study teams to visit mining operations during the study phase. The aim is to gain an insight into what works well. This is also an opportunity to learn from the mistakes of others and thus avoid the same pitfalls. The justification for the mine visit is to improve the value of the next project.

In an operating mine, managers may want to know how they are faring compared to other operations. This could be within the same company or any other mine external to the company. Some organisations claim to be industry leaders, while others will be 'close followers'. Benchmarking is an essential tool to confirm these claims or concepts.

Industry conferences provide an excellent platform for mines to showcase their latest ideas. Some papers will highlight improvements over past projects. Others may be written with the aim of luring investment interest. Many engineers who read the proceedings are seeking to add value for their own projects.

An old saying is "don't believe everything you read in the papers". Whilst this was referring to newspapers, there are some significant differences between conference papers. Reputable conferences tend to have a system of peer review of papers. This process can test the claims or statements made. Some 'commercial' conferences are not as thorough and allow 'advertising material'.

The aim of this paper is to discuss the relevance of benchmarking data associated with block or panel caving mines and projects, although there will be some issues that are relevant to all underground mining projects.

\section{Benchmarking basics}

Benchmarking is a straightforward process consisting of three basic steps.

1. Gather or access data.

2. Rank performance or design metrics in order.

3. See where your chosen design or actual metric sits compared to the data spread.

There are some comprehensive databases around the industry. Although, like all tools, they need constant updating. They should account for changes, productivity improvements and advances in technology. Some databases belong to engineering consultancies. Others are a product of research or collaboration. 
Figure 1 shows an example of benchmarking; development advance rates achieved in a range of underground mines. The highlighted results show improvements in performance from an initial baseline value of daily advance rate on a specific project.

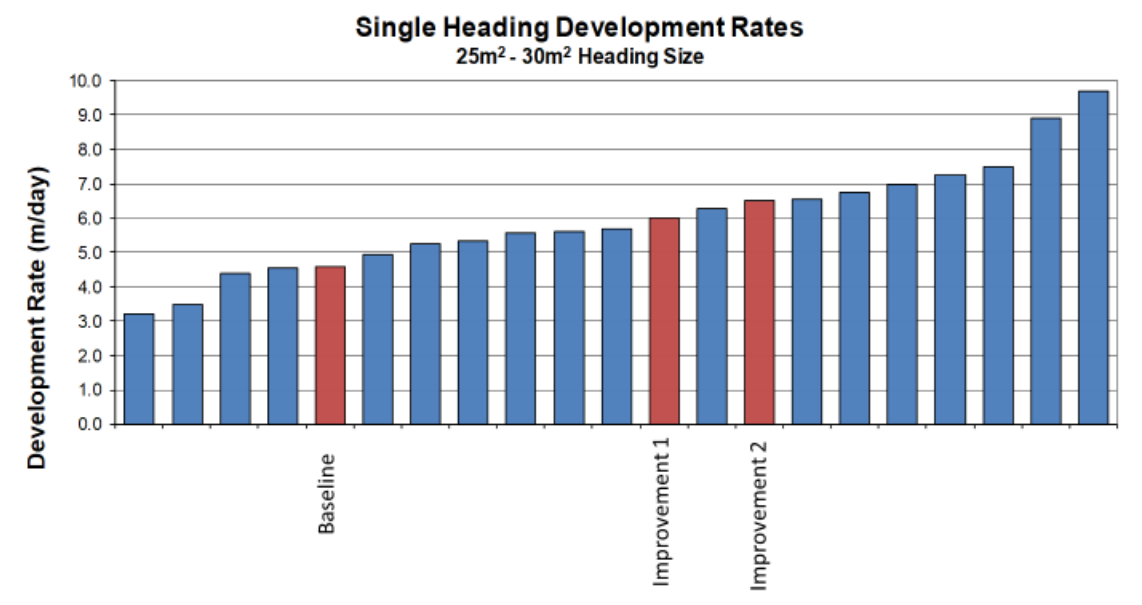

Figure 1 Development advance rates

This benchmark data comes from multiple sources. One source was a consultancy database. Another was various mines within the company that managed the project. The final source was from data obtained by the project team whilst visiting different mining operations.

Using data from multiple sources makes the comparison appear comprehensive. But are the different rates quoted comparable? Consistency of data is discussed in Section 2.1.2.

\subsection{Issues with benchmarking data}

What are the key issues to be aware of whilst benchmarking? The context and consistency of benchmarking data need to be appreciated.

\subsubsection{Context}

The physical location of an orebody will have an impact on many parameters. These are issues outside the control of the project team. The issues can be managed, but they will influence the project design and cost. Some of the more common aspects are suggested below.

\subsubsection{Style of mineralisation}

This includes all the basic parameters of the orebody. The geological setting and geotechnical characteristics of the orebody and the surrounding rocks are fundamental to mine design. This will influence tunnel support requirements and productivity. The depth below surface, regional stresses and geothermal gradients can all have significant impacts on aspects of mine design, performance and cost. The commodity itself may also have an influence on how the ore is mined, treated or transported.

\subsubsection{Location}

The geographic location of mines must also be considered when analysing benchmark data. Currency (exchange rate fluctuations) can skew cost comparisons.

The local culture may play a role in the basic functioning of the mine or manning levels. Is there a preference for higher levels of employment? If so, there may be resistance to the concepts of automation which a project team may think efficient. Does the country have a good reputation for schooling, supporting an expectation of a well-educated workforce? In some countries, it may be necessary to factor in additional costs for provision of extensive training facilities. 
What about local infrastructure (power, transport routes, engineering services, and suppliers)? In remote locations, the mine or project may need to budget significant capital or operating costs, whereas, in developed areas, the services may be readily available and cheap.

Is the legislation applied to the mining industry restrictive? Can productive approaches be explored with regulators or must everything be approved prior to being allowed? These may have project scheduling implications (waiting for permits/approvals) or cost implications if equipment must meet stringent local standards.

\subsubsection{Climate}

Climate can affect operating or capital costs of new mines and conditions need to be considered. Some relevant questions are:

- What are the typical ambient temperatures?

- What is the variation from summer to winter?

- How much rainfall can be expected?

- How is the rainfall distributed?

- Does weather affect operability of the mine or logistical transport routes?

\subsubsection{Comparing projects - context}

Let us consider two mines, both with a copper porphyry style mineralised zone. Also, assume that tonnage and grade of the resources are similar. How reliably can one be benchmarked against the other? What production rate can each project support? What should a typical cost per tonne be?

The first project is in a tropical, high-rainfall area. The orebody is in a remote, mountainous region at approximately $3,500 \mathrm{~m}$ above sea level. Due to altitude, the virgin rock temperature (VRT) is around $25^{\circ} \mathrm{C}$. It operates within a changing political environment. It is a 'brownfield' project and the mine has an experienced workforce.

The second one is in an arid desert environment. It is close to well-established infrastructure and the orebody is $2,000 \mathrm{~m}$ below surface with a VRT of $80^{\circ} \mathrm{C}$. It is in a politically mature setting such as the USA. This is a greenfield project and must still recruit a workforce.

Even once the geological, geographical and geopolitical setting is appreciated, it is also important to understand the 'enabling circumstances' around any specific parameters. A mine that has multiple access declines and adits will have logistical flexibility for material transport. A mine which only has two deep shafts for access will be constrained. One mine may be able to drain water out of the mine using gravity, while the other will have to pump water out. One will require significant cooling, but not the other.

Comparisons will be inevitable. However, there must be differences in capital required, operating costs and productivity.

\subsubsection{Consistency and composition}

Consistency of data is essential for meaningful benchmarking. Grabbing headline numbers and taking them at face value can lead to major misinterpretations.

A good database contains data that has been analysed in detail. Costs are broken down to individual activity level (cost elements). Then, the cost per tonne mined or per metre advanced can be reconstructed. This ensures that headline costs are made up of the same elements and are truly comparable. This takes time and effort, and requires an investment in information. An example of this would be the Australian Mining Consultants' (AMC) underground mining database. 


\subsubsection{Example of in-house benchmarking}

Many years ago, DeBeers underground mines were internally comparing basic performance. Areas of comparison included parameters such as development advance rates, cost per metre developed and load-haul-dump unit (LHD) tyre life.

When the mine managers met and discussed issues in detail, it was apparent that one mine did not include support cost in the development cost per metre, whereas the others did. Similarly, when LHD tyre life was analysed, it was discovered that one mine ignored punctures when calculating tyre life as the manager wanted to see the 'real' wearing life of the rubber tread.

Simply comparing the headline numbers on development cost per metre or LHD tyre life in hours in the example above gave senior management a distorted view of actual performance. Only once the data had been rationalised to ensure consistency did it become a useful comparison.

\subsubsection{Availability and utilisation}

Different companies (or engineering managers) calculate equipment availability differently. This is probably the most common example of inconsistency in comparative data.

Some operations may claim 70,80 or even $90 \%$ fleet availability, but what is the denominator? Is it:

- Calendar hours.

- Planned shift hours.

- Machine scheduled hours.

Also, are outages for major overhaul/rebuild included? Each method of calculation will yield a different availability number.

The definition of unavailable time also differs. Is it from:

- When the unit breaks down.

- When the report of the breakdown is received by the responsible maintenance group.

- When repair work starts.

A similar issue is often seen with utilisation. What constitutes that denominator? Is it calendar hours, hours available for use or does it only include hours scheduled for use (or only those where there is an operator available)?

These examples indicate that some statistics (or data) can be selective in what they purport to measure. One should always be aware of what is being measured and how numbers are calculated before using them to benchmark.

\subsection{Issues with benchmarking comparisons}

It is normal for operations to benchmark performance against competitors? If benchmarking data used has the same base and composition, comparisons are relevant.

\subsubsection{Benchmarking against operations}

In the context section above, it was noted that there will be differences between mines based on location and local conditions which are beyond the control of the mine operators. That doesn't mean that one mine should not be compared with another.

What is important is to understand what specific design or performance aspects should be comparable and where there will be obvious differences. Many mines and projects do this quite successfully. 
Benchmarking a study against existing operations is a normal part of a study. It gives the project team confidence in their assumptions. It can assist when attempting to gain project approval. If the project is not at the 'extreme' end of the benchmarked parameters, this may indicate that the project is 'less risky', as the levels of performance have been achieved elsewhere.

\subsubsection{Benchmarking against studies}

A study that has been benchmarked against another study has very limited value. The exercise may demonstrate that one set of assumptions is similar to another set of assumptions. Both may be totally incorrect or inappropriate.

Care must be exercised when doing a literature search for the benchmark data. Some mines publish prolifically and are keen to advertise progress. In such cases, it is important that the most recent paper is used.

Many papers published prior to a mine coming into production will often take an optimistic view and assume all aspects will be implemented as planned. Very few mines are developed, constructed and operated exactly as proposed in the feasibility study (FS). Invariably, there are changes made during project development. Some are a result of cost-saving measures, while others may result from unforeseen conditions.

\subsubsection{Selective benchmarking}

Sometimes referred to as 'cherry picking', only the best things from a suite of benchmarked parameters are reported as benchmarks. This is normally used to justify the use of assumptions that have already been achieved within the industry.

Assume a study selects the highest rate of development advance achieved at one mine and uses it as a basis for their study. It then assumes the fastest rate of production ramp-up achieved from a different mine. It then assumes the lowest mining unit cost achieved at a third mine.

The study then feeds these parameters into the project schedule and cost model. Does this approach have any real value?

If the study does not know how the development rate was achieved and what conditions allowed the production to ramp up, there will be a scheduling issue. Unless it is understood how the basic activities and associated costs link together and can be replicated, the new project will be set up to fail.

Most parameters in cave mines are interlinked. Maximising one parameter will have a negative effect on another. An example is the widening of drawpoint spacing. This will improve drawpoint pillar stability but will reduce draw interaction. This will have an impact on recovery. Cherry picking 'best practice' for multiple parameters (from different operations) in isolation, and then combining them without understanding the interdependencies, is irresponsible.

\section{Benchmarking data issues for block or panel caving mines}

Some of the limitations of benchmarking block and panel caving mines are discussed in the following section.

\subsection{Limited dataset}

There is a relatively limited pool of operations and projects to draw from. Figure 2 shows the traditional pool of approximately 25 block or panel caving operations and 12 projects. How good is the data from these sources and are they valid benchmarks? Whilst it is recognised that many of these operations have more than one cave, the relevance of the operating timeframes should also be considered. 


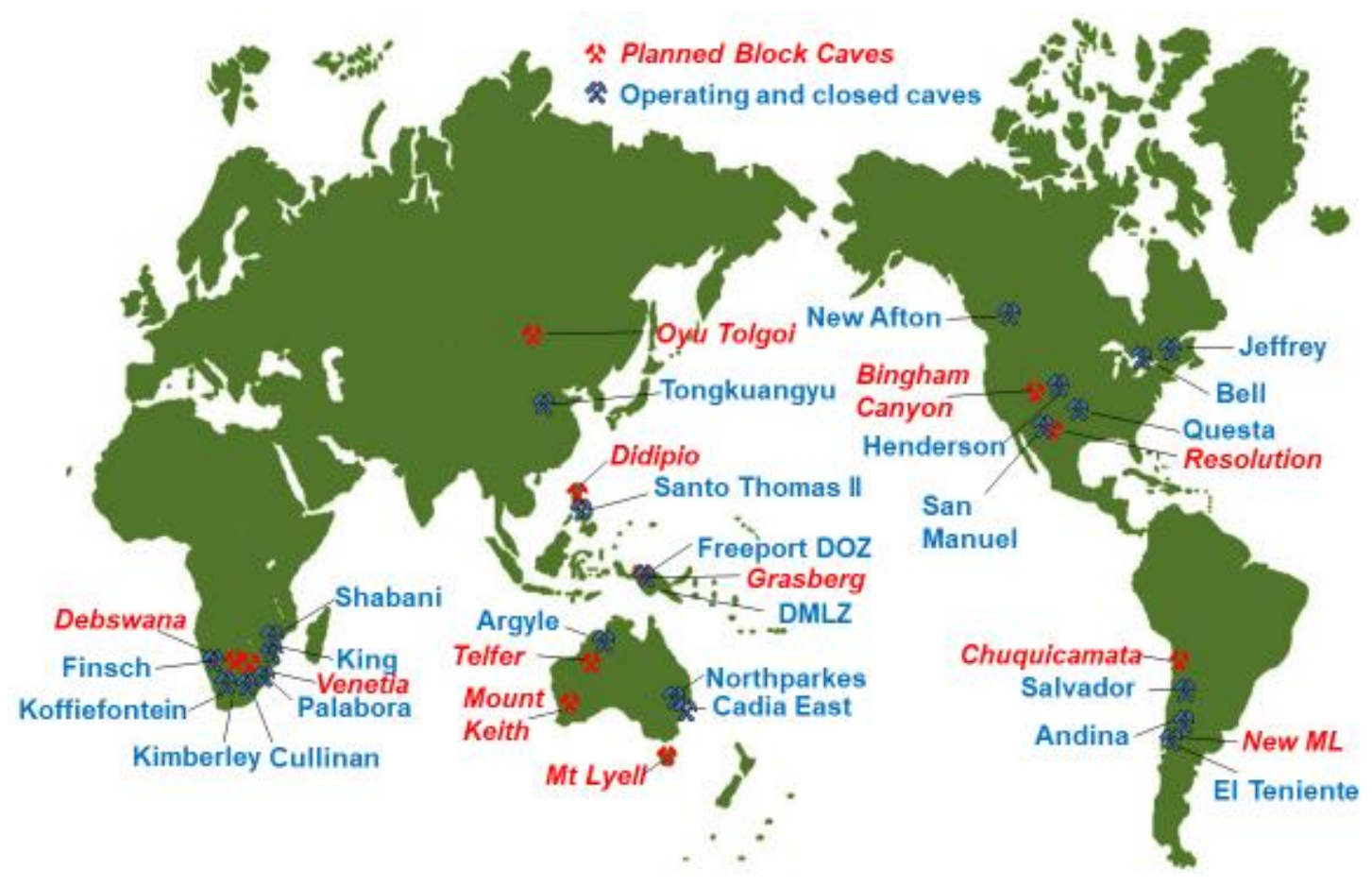

Figure 2 Caving operations and projects

How relevant are the operating statistics or design parameters from a mine that was active 50 years ago in today's modern environment?

The most comprehensive benchmarking exercise in caving was undertaken by Flores and Karzulovic (2000). Their work showed that there had been a shift over time with parameters such as production drift spacing, drawpoint spacing and block height (Figures 3 to 5).

The time periods indicated in these figures are important. The oldest (pre-1970) are the lightest bars. The medium bars cover the period 1970 to 1990, and the dark bars are post-1990 data.

The time periods indicated in these figures are important. The trends have been influenced by a global shift to caving into more-competent orebodies. Some trends reflect an increase of mechanised equipment being used instead of manual labour. Prior to 1970, there was very little mechanisation in caving mines.

Some of the benchmarked parameters since 1990 are influenced by the increased number of caving mines in more-competent ground. Examples include Palabora, Northparkes and El Teniente moving into primary ore instead of supergene material.

Twenty years after this benchmarking exercise, the contemporary trends may appear to be even more extreme. These benchmark graphs do not include mines designed or constructed after 2000, including Freeport's Deep Mill Level Zone (DMLZ) and Grasberg Block Cave (GBC) mines, New Afton, Cadia East and Codelco's El Teniente New Mine Level and Chuquicamata. 


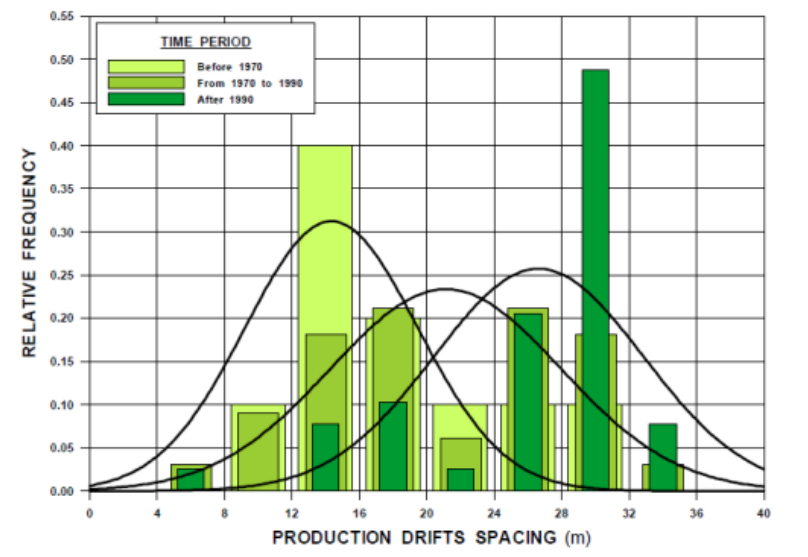

Figure 3 Production drift spacing (Flores \& Karzulovic 2000)

Figure 3 shows that production drift spacing has increased from a mean of $14 \mathrm{~m}$ (pre-1990) to $27 \mathrm{~m}$ in 2000 .

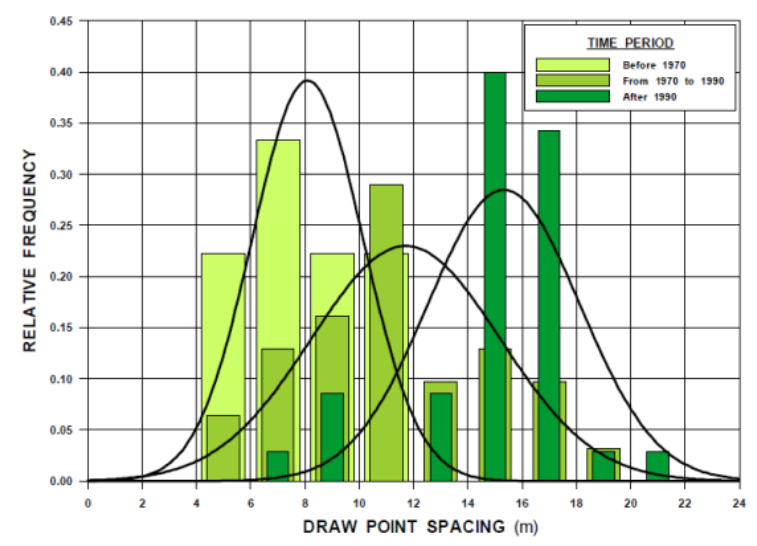

Figure 4 Drawpoint spacing (Flores \& Karzulovic 2000)

Figure 4 indicates that drawpoint spacing has also increased from a mean of $8 \mathrm{~m}$ (pre-1990) to $15 \mathrm{~m}$ in 2000.

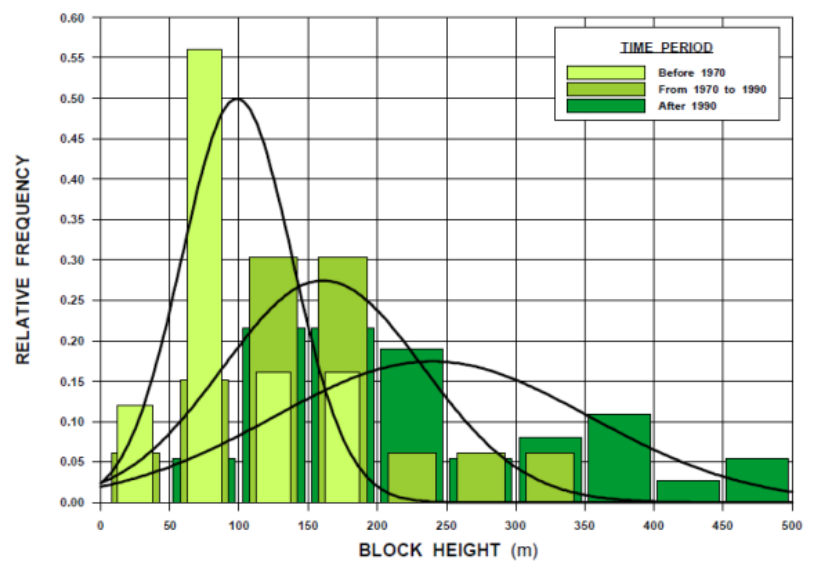

Figure 5 Block height (Flores \& Karzulovic 2000)

Figure 5 shows a trend of increasing block heights from a mean of $100 \mathrm{~m}$ (pre-1990) to $250 \mathrm{~m}$ in 2000. When considering block cave height, the material type is certainly relevant. The premise is that more-competent rock provides a more-stable drawpoint for a longer duration, thus allowing longer drawpoint life and more tonnage to be pulled. Since 2000 , many mines have planned $500 \mathrm{~m}$ high blocks, yet no evidence of successful extraction of the contents of those tall columns has been published. Some mines continue to 'push the 
envelope' with Cadia East planning over 800 m block heights (Catalan et al. 2012). Unfortunately, it will take several years (until around 2030) to establish if this has been successful.

The problems of high initial capital cost and long lead times present financial pressures on most new projects (Ross \& deWolfe 2016; Stewart \& Butcher 2016). The requirement to improve capital efficiency has also influenced mine designers to support increased drawpoint and drift spacing (less development) and increase block heights (more tonnes per constructed drawpoint).

The use of larger equipment requiring larger excavations has also influenced drawpoint spacing, even though Laubscher (2000, ch. 28 , p. 16) states that, "The size of the LHD is a function of the permissible layout. It is not based on the independent wishes of management".

The readily available caving benchmarking data is somewhat dated. However, due to the time taken for projects to be developed, the feedback loop is often incomplete.

\subsection{Lack of feedback}

With the small number of active caving mines, there are few opportunities to see all aspects of the caving cycle while a study is being performed. As mentioned previously, there is a tendency to increase the benchmarking dataset by including studies and projects being developed.

The timeframes to take a major project from conceptual study through to commencement of production may be more than a decade. PT Freeport's GBC is planned to achieve full production in 2024, some 20 years after the portals were commenced (Brannon et al. 2016). The FS for GBC was completed in 2008. The designers will only get feedback on some key assumptions 15 to 20 years after they were made. In the meantime, other studies regularly use GBC as a source of benchmarking data, even though many assumptions used in the FS will not be verified for another decade.

Even on shorter-life projects, little feedback is available in the form of published material that provides a comparison of planned and actual data. One example from Northparkes describes seven key design aspects and comments on changes made to design from the FS. It highlights some design flaws and describes where areas exceeded expectations (Ross 2008).

Unfortunately, some studies infer that benchmark information from another study represents what has been achieved in industry. This is plainly not the case as there can be significant variation from what was envisaged in a caving study compared to what actual levels of performance are achieved. Hence, caution should be exercised when benchmarking against caving studies.

\section{$4 \quad$ Benchmarking of caving projects}

Mining companies, in the quest for improved shareholder return, are looking for higher production rates from new underground mines. Minimising capital and maximising production has been a focus of project teams. "Issues facing caving projects include high initial capital costs, long development periods and significant technical challenges. These issues tend to make it difficult to present an attractive business case for such a project", according to Ross and deWolfe (2016, p. 51).

The context of the project, as described in Section 2.1.1, will dictate many of the costs and development required, and potential production levels. Most project teams will identify the levers that drive value and then strive to use them to improve project returns.

In basic terms, these are generally:

- Initial development.

- Cave ramp-up.

- Production output. 
The desire for rapid development is common across most underground projects and not unique to caving mines. Development rates from three recent projects and a historical example of high-speed development were benchmarked by Ross (2014). The historical rate (over $700 \mathrm{~m} / \mathrm{month}$ ) was significantly higher than the contemporary mines. Components of the cycle were analysed along with various productivity measures. Some differences in work methods, equipment design and organisation were discussed.

Production output will ultimately be constrained by footprint geometry, available column heights, and grade. This will not be dealt with in this benchmarking paper.

The financial pressure to ramp a project up quickly means that tonnage ramp-up is a key concern and one that is examined regularly.

Most feasibility studies will contain a graph of tonnage ramp-up like Figure 6.

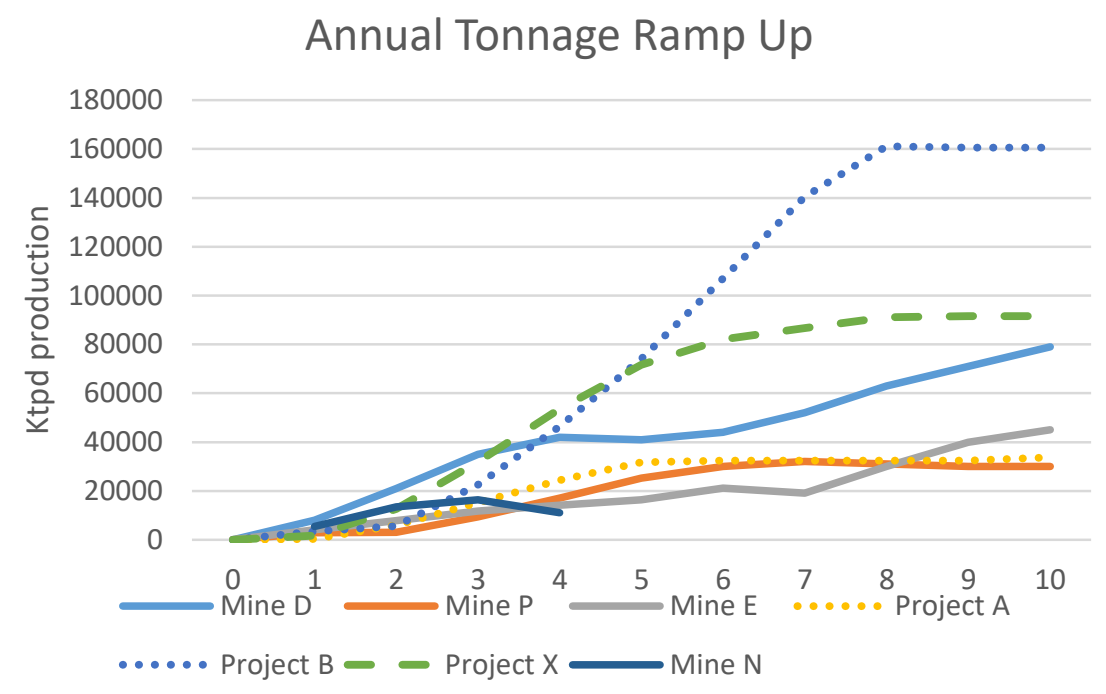

Figure 6 Annual tonnage ramp-up in ktpd

This shows how Project $X$ (dashed line) compares to other mines (solid lines) and studies (dotted lines). At first glance, one may think 'fast but reasonable'. A key point to note is that Project $X$ exceeds all the other benchmark ramp-ups by year four and is similar to the best (Project B) in year five. It should be noted that the best beyond year five is a project that must still be built and may experience all sorts of issues, which will only be verified in 5 to 10 years' time. Also, the first few years of ramp-up tend to affect net present value more than later years, due to discounting.

How do study teams estimate the rate of ramp-up, and is there value in benchmarking?

The three key drivers for ramp-up tonnage are:

- Undercutting rate.

- Drawbell construction rate.

- Cave propagation rate.

These will be discussed in more detail. 


\subsection{Undercutting}

The rate of undercutting is a function of undercut mining front width and advance rate. The most generally used measure is $\mathrm{m}^{2} /$ month. The area undercut is the product of face advance and undercut face length.

The face advance rate $(\mathrm{m} / \mathrm{month})$ is an important measure as an undercut that moves too slowly will allow abutment stresses to damage the extraction level. An undercut that moves too quickly may induce high levels of seismicity. Most successful undercuts appear to have face advance rates of between 8 to $10 \mathrm{~m} / \mathrm{month}$.

Araneda and Sougarret (2008) provide some comparisons of mining front widths and make comments regarding lessons learned. Their comments refer to an analysis of several undercuts that was conducted in a workshop in Phoenix. The basic conclusion was that mines that had undercut widths more than $400 \mathrm{~m}$ invariably experienced major problems. All the examples of 'successful' undercuts were less than $300 \mathrm{~m}$ wide.

A good rule of thumb for a successful undercut advance rate is 2,500 to $3,000 \mathrm{~m}^{2} / \mathrm{month}$.

Figure 7 shows a comparison of undercutting rates at different mines.

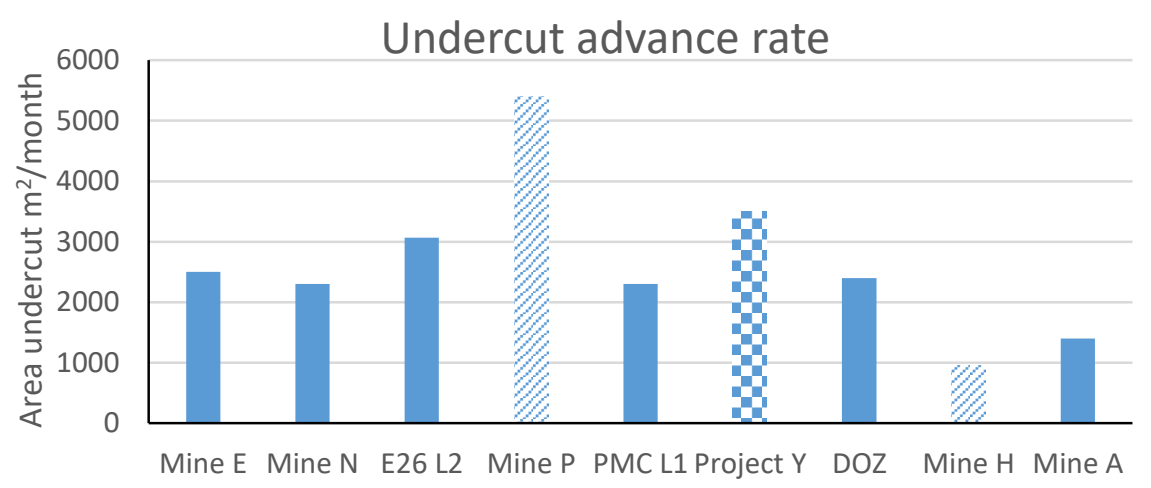

Figure 7 Undercut advance rate

The extremes (Mines $\mathrm{P}$ and $\mathrm{H}$ ) are post-undercut scenarios and are subject to different constraints. It would not be valid to compare different types of undercut in a benchmarking exercise. Although, a FS would probably consider alternatives. All the remaining undercuts are advance undercuts, and Project $Y$ has a reasonably aggressive FS planned rate. It is quite likely that this will not be achieved.

Some of these undercuts were advanced over several years. Are these benchmark values the average, the peak or the mean values?

Figure 8 shows the Northparkes E26 Lift 2 planned and actual undercutting rates.

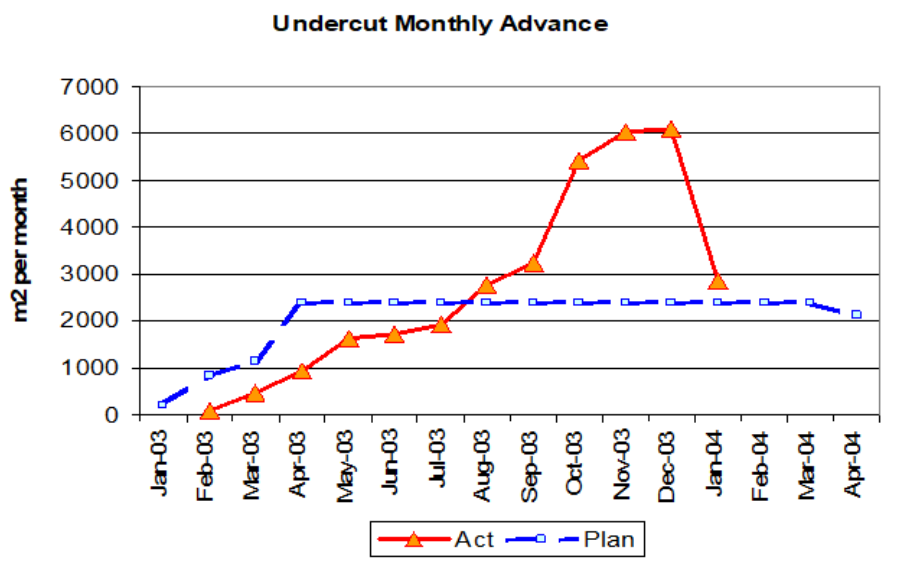

Figure 8 Northparkes E26 Lift 2 planned and actual advance rates (after Ross 2004)

Silveira (2004) describes the Northparkes E26 Lift 2 undercutting process and lists the critical success factors. It is important to understand what factors drive performance, not just the final numbers. 


\subsection{Drawbell construction}

The drawbell is the key excavation that connects the extraction level with the undercut. It is important to recognise the interrelationship between drawbell design and undercut design. Current trends are to use the undercut to 'shape' the top of the drawbell across the major apex (above the undercut level) as part of an 'inclined' undercut configuration (advance approach). This contrasts with the historical approach of blasting the undercut down into the drawbell in a post-undercut approach.

Drawbell construction is the one parameter that is probably the most misunderstood and most difficult to reliably benchmark. In this example, we will consider three different mines that all use the advanced undercut strategy.

Many study teams look at mature caving operations such as Freeport's DOZ mine and assume that five drawbells per month is a 'normal' rate. The DOZ expansion to $80 \mathrm{ktpd}$ and drawpoint opening rate is covered by Casten et al. (2008). It can be seen that an overall average rate of three drawbells per month was obtained in the period from 2000 to 2006 . This was the time that the mine was ramping up to $25 \mathrm{ktpd}$ and then on to $35 \mathrm{ktpd}$. The opening rate increased to five per month for the years 2007 to 2009 to enable the expansion to $50 \mathrm{ktpd}$ and then up to $80 \mathrm{ktpd}$. This increase in drawbell development rate was driven by the need to have between 550 and 625 active drawpoints available to achieve this tonnage.

Whilst the rate of five drawbells per month is regularly used as a benchmark rate, the factors that enabled this performance need to be understood. Contributing factors were:

- Management commitment to expanded production.

- Operating mine (with large footprint).

- Experienced crews.

- Multiple access points into the mine.

- Availability of onsite concrete batching plants.

- Major facilities (crushers, workshops, etc.) were already completed.

Not all projects will have these enablers, and thus may find the achievement of the rate of five drawbells per month very challenging.

\subsection{Drawbell construction measurement}

How is the number of drawbells per month derived? The simplest and most common measure is the number of drawbells that are blasted during a month. However, that is not the full picture. There are many factors that influence the time it takes to develop, construct and blast a drawbell. They include:

- Ground quality.

- Stress regime.

- Support specifications (number of layers/support elements).

- Work sequencing and crew availability.

- Roadway construction requirements.

- Curing time for concrete/shotcrete.

Most schedules contain between 30 and 50 days of work required for each drawbell (four to seven weeks). However, many drawpoints are still to be blasted three to six months after commencement due to workflow and scheduling constraints.

Two specific examples are examined in more detail in the following section. 


\subsubsection{Northparkes E26 Lift 2}

Northparkes Mines (NPM) Lift 2 constructed an average of 4.9 drawbells per month, from when the first drawpoint turn-outs were developed (August 2003) to the final drawbell blast (30 July 2004).

A total of 20 drawbells were fired in a single month (July 2004), but to assume this is a sustainable rate is ludicrous. It was only possible because all undercutting and roadways had been completed, all trough slot holes had been drilled and nearly all the support and drawbell drilling had been completed at the start of the month. All that was left to be done was to charge the bells, connect up and blast.

If one measures from the first drawbell firing (29 February 2004) to the last, 59 drawbells were blasted in five months, which equates to a rate of almost 12 drawbell blasts per month. This is how most operations would normally report their rate. If the last month is removed ( 20 drawbells), a more representative level of 9.7 results.

However, the rate of 9.7 does not include all the time that was spent completing various activities in multiple drawpoints leading up to the blasting of the first drawbell. A total of seven months elapsed from the first drawpoint turn-out being broken (August 2003) until the first drawbell was blasted (end February 2004). The rate from start to finish, excluding the extreme final month results in a rate of 3.5 drawbells per month.

There is such a high variance because of the relatively short duration of the drawpoint construction period. Larger footprints and longer construction times will see less variance. Which value should be used to benchmark against?

\subsubsection{Palabora Lift 1}

When examining the Palabora Lift 1 results, an overall rate of 3 bells per month was achieved. This includes the time from commencing drawpoint development (February 2000) to blasting the first drawbell. The rate increases to 3.4 if it is calculated from after the first drawbell is blasted (July 2000) until the final firing in July 2004.

In an advance undercut scenario, many mines start the drawbell construction sequence by breaking away a drawpoint turn-out ahead of the undercut abutment stress front. This gives them a head start compared to mines that must wait until the breakaway position is in the 'stress shadow'. This can appear to reduce the construction time for drawbells. How much development can be done in the drawpoint pillar ahead of the undercut will depend on the stresses induced and the rock mass properties. If too much material is excavated from the drawpoint pillar ahead of the abutment stress, the pillar will be compromised. The amount of rehabilitation required may increase the time and cost it takes to ultimately open the drawbells.

The construction of an extraction level during cave start-up becomes quite chaotic. Just ask any supervisors or managers who have lived through this activity. Even if regular (daily) planning and coordination meetings are held, priorities change rapidly. There are different work crews with different priorities, all trying to get as much done as possible in a restricted work area. Access is often restricted, especially after tonnage is being drawn from the first drawbells.

The issue of logistics is often neglected until extraction level construction begins. Concrete and shotcrete delivery tends to be the constraining factor for construction activity.

Benchmarking of drawbell opening rates are of little value. Study teams should focus on what excavation sequence, level of support, construction requirements and logistics are appropriate for their specific project.

A rule of thumb is 'three drawbells per month is achievable, four is typical and five is good'. It would be unusual to expect more without a detailed methodology assessment. 


\subsection{Cave propagation}

What area must be undercut to allow the cave to propagate? This is an important parameter when planning a caving mine. Obviously rock quality is a major factor. Data points from many caves have effectively been benchmarked and plotted to create stability curves. This benchmarking was taken further to include smaller openings and 'non-caving' mines. The Laubscher and Mathews curves are good examples of empirical benchmarking and their use is described by Brown (2000).

Once a cave has been undercut beyond the critical hydraulic radius, continuous caving can occur. The drawpoints under the undercut area can then start to produce. However, the rate of production should be constrained by the cave propagation rate. This means that the tonnage pulled from the drawpoints should not exceed the rate that the cave propagates. If the rate of draw is too high, an air gap will form above the caved material and the risk of an air blast is present. This often constrains the rate of production.

Cave propagation is the third main factor affecting cave tonnage ramp-up. How fast will the cave propagate? Can the rate be accelerated artificially? That is a question many study teams debate. Even with modern software and geotechnical models, the answers are not accurate. Most tools are not effective when dealing with time-dependent situations. Incomplete orebody knowledge also hinders the effectiveness of modelling.

Measurement of seismicity can provide indications of how rapidly the cave is propagating, but it cannot provide definitive position. Seismicity indicates where rocks are breaking, but not where the physical cave back or zone of loosening is present. Perhaps cave trackers and networked smart markers may provide this information in the future (Whiteman et al. 2016).

Levels of seismicity movement above the cave back range from around $15 \mathrm{~m} /$ month (Glazer 2004) through to $80-90 \mathrm{~m} / \mathrm{month}$ (Hudyma et al. 2007).

One technique that has been used in several cave mines is preconditioning. Whilst it was originally employed with the aim of improving secondary fragmentation, it has proved effective in helping manage seismicity. In some circumstances, it has also assisted in cave propagation.

Obvious factors that affect the propagation rate are natural, such as the rock strength, number and nature of discontinuities, and stress (in situ and mining-induced). Lett and Capes (2012) noted that caving at Ridgeway was heavily influenced by natural fault features.

The trend for cave propagation appears to be 'faster than you might expect', but cave propagation rate is so site specific, benchmarking is irrelevant.

\subsection{Benchmarking normalisation}

Most cave mining projects and studies are subjected to extensive review due to the risks and capital involved. Reviewers will also have their own 'database' or rules of thumb, so a benchmark outlier, or extreme value, will probably be a point of contention.

To reduce the perceived level of risk, most project approvers prefer to remain within normal benchmark limits. This begs the question 'how will the industry improve if all new mines are planned within existing benchmarks'?

In my view, a company, manager or leader must take a risk. They should apply a novel approach or piece of equipment. This needs to be done in a structured, systematic manner, such as that described by Tota (1997). There is a risk that it may fail, so, a backup plan should also be formulated. The most likely catalyst for step change is a disruptive technology that will shatter the norms. It will still take courage to introduce it into a new mine. 


\section{Conclusion}

To perform a benchmarking exercise properly, the source of the data used should be understood. It takes time and effort to understand how parameters such as unit costs or availabilities are built up. Some commercial databases are available, and these may be accessed via a variety of consulting organisations.

When benchmarking operational parameters in mines, the context in which the mine operates needs to be understood and care taken if comparisons are made.

The dataset on caving mines may be too small to be considered reliable. There will be natural geological and geotechnical conditions making each site unique. This further reduces the potential for reliable benchmarking of block cave mines. Benchmarking against studies can be misleading as the values in a study often take too long to be verified in the field.

In some areas of caving, empirical approaches and rules of thumb provide as much guidance as a benchmarking exercise.

Benchmarking has a role to play but the data, context and limitations need to be understood.

The industry needs to employ novel techniques or technology if it is to improve on benchmark norms. This will present some risk. As the old saying goes, 'no risk, no reward'.

\section{References}

Araneda, O \& Sougarret, A 2008, 'Lessons learned in cave mining at the El Teniente mine over the period1997-2007', Proceedings of MassMin 2008, Luleå University of Technology, Luleå, pp. 43-52.

Brannon, C, Firdausi, H, Pascoe, N \& Yuniar, A 2016, 'Development and construction update of the Grasberg Block Cave mine' Proceedings of MassMin 2016, The Australasian Institute of Mining and Metallurgy, Melbourne, pp. 625-633.

Brown, ET 2000, Block Caving Geomechanics, Julius Kruttschnitt Mineral Research Centre, Brisbane, pp. 126-138.

Casten, T, Rachmad, L, Arkadius, T, Osborne, K \& Johnson, M 2008, 'PT Freeport Indonesia's Deep Ore Zone mine - expanding to 80,000 tonnes per day', Proceedings of MassMin 2008, Luleå University of Technology, Luleå, pp. 265-274.

Catalan, A, Dunstan, G, Morgan, M, Green, S, Jorquera, M \& Thornhill, T 2012, 'An "intensive" preconditioning methodology developed for the Cadia East panel cave project, NSW, Australia', Proceedings of MassMin 2012, Canadian Institute of Mining, Metallurgy and Petroleum, Westmount.

Flores, G \& Karsulovic, A 2000, Geotechnical Guidelines for a Transition From Open Cut to Underground Mining: Benchmarking Report, report to the International Caving Study II, Julius Kruttschnitt Mineral Research Centre, Brisbane.

Glazer, S \& Hepworth, N 2004, 'Seismic monitoring of block cave crown pillar - Palabora Mining Company, RSA', in A Karzulovic \& MA Alfaro (eds), Proceedings of MassMin 2004, Instituto de Ingenieros de Chile, Santiago, pp. 565-569.

Hudyma, M, Potvin, Y \& Allison, D 2007, 'Seismic monitoring of the Northparkes Lift 2 block cave - part 2 production caving', Proceedings of the 1st International Symposium on Block and Sub-Level Caving Cave Mining, The Southern African Institute of Mining and Metallurgy, Johannesburg, pp. 303-334.

Laubscher, D 2000, Block Caving Manual, report to the International Caving Study, Julius Kruttschnitt Mineral Research Centre and Itasca Consulting Group Inc., Brisbane, p. 16.

Lett, JL \& Capes, GW 2012, 'Characterisation of caving and subsidence for operational enhancements at the Newcrest Ridgeway gold mine', Proceedings of MassMin 2012, Canadian Institute of Mining, Metallurgy and Petroleum, Westmount.

Ross, I 2004, 'Northparkes Lift 2 development', Proceedings of the Innovative Mineral Developments Symposium, Australasian Institute of Mining and Metallurgy, Melbourne, pp. 53-69.

Ross, I 2008, 'Northparkes E26 Lift 2 Block Cave - a case study', Proceedings MassMin 2008, Luleå University of Technology, Luleå, pp. 25-34.

Ross, I 2014, 'Development - back to basics', Proceedings of the 12th Underground Operators Conference, The Australasian Institute of Mining and Metallurgy, Melbourne, pp. 67-73.

Ross, I \& deWolfe, V 2016, 'Supercaves - benefits, considerations and risks', Proceedings of MassMin 2016, The Australasian Institute of Mining and Metallurgy, Melbourne, pp. 51-58.

Stewart, CA \& Butcher, RJ 2016, 'Block cave evaluation', Proceedings of MassMin 2016, The Australasian Institute of Mining and Metallurgy, Melbourne, pp. 809-815.

Silveira, A 2004, 'Undercutting at E26 Lift 2 Northparkes', Proceedings of MassMin 2004, Instituto de Ingenieros de Chile, Santiago, pp. 410-414.

Tota, E 1997, 'Northparkes mines - new performance benchmarks for underground mining', Proceedings of the Aus/MM Annual Conference, The Australasian Institute of Mining and Metallurgy, Melbourne, pp. 57-64.

Whiteman, D, Talu, S, Wilson, M, Watt, G, van AS, A \& Kuiper, P 2016, 'Cave tracker flow monitoring system installation at Argyle Diamond Mine', Proceedings of MassMin 2016, The Australasian Institute of Mining and Metallurgy, Melbourne, pp. 479-488. 